Research, Society and Development, v. 7, n. 5, p. 01-18, e1275317, 2018

ISSN 2525-3409 (CC BY 4.0)

\title{
Formação de professores e o ensino investigativo na química: reflexões e estratégias
}

Teacher training and inquiry in chemistry: reflections and strategy

Carlos José Trindade da Rocha

Universidade Federal do Pará, Brasil

E-mail: carlos.rocha@iemci.ufpa.br

Maisa Helena Altarugio

Universidade Federal do ABC/São Paulo, Brasil

E-mail: maisahaufabc@gmail.com

João Manoel da Silva Malheiro

Universidade Federal do Pará, Brasil

E-mail: joaomalheiro@ufpa.br

Recebido: 13/03/2018 - Aceito: 22/03/2018

\section{Resumo}

Neste trabalho apresentamos uma investigação sobre análise de uma estratégia de ensino investigativo na formação de professores de química em uma Universidade pública federal do Estado de São Paulo, com sete alunos da licenciatura em química durante um quadrimestre. A metodologia no estudo é de natureza qualitativa do tipo análise do discurso. Os dados são compostos pela análise da práxis do plano de aula docente na disciplina Experimentação e Ensino de Química (EEQ). Os dados obtidos revelam o enriquecimento no processo de formação inicial, motivando a participação e comprometimento dos estudantes com as atividades. $\mathrm{O}$ ensino investigativo se diferenciou por envolver o bom planejamento do professor e alunos na construção do conhecimento científico, e que é possível como estratégia da aplicação de procedimento didático no trabalho docente.

Palavras-chave: Formação de professores; Ensino investigativo; Química.

\footnotetext{
Abstract

In this work we present an investigation on the analysis of an investigative teaching strategy in the training of chemistry professors at a federal public university in the State of São Paulo, with seven undergraduate students in chemistry during a four - month period. The methodology in the study is qualitative in nature of the discourse analysis type. The data are composed of the praxis analysis of the teaching lesson plan in the discipline Chemical Experimentation and Teaching (CET). The obtained data reveal the enrichment in the initial formation process, motivating the participation and commitment of the students with the activities. The investigative teaching was distinguished by
} 
involving the good planning of the teacher and students in the construction of scientific knowledge, and that it is possible as a strategy of the application of didactic procedure in the teaching work.

Key words: Training; Inquiry; Chemistry.

\section{Introdução}

A abordagem ao ensino de Ciências por investigação ainda não está bem estabelecida no Brasil (MUNFORD; LIMA, 2008). Conforme Sá, et al. (2007) existem poucos artigos publicados sobre o tema. Isto se deve ao fato de que o ensino por investigação começou a ser debatido amplamente apenas após os PCN (1998) e da publicação dos documentos que orientaram a reforma da educação em Ciências nos Estados Unidos.

Atualmente a investigação dirigida continua sendo um estilo central defendido para o ensino e aprendizagem das ciências (HOFSTEIN; LUNETTA, 2004; CORTÉS; DE LA GÁNDARA, 2007). O termo utilizado para denominar esse tipo de aprendizado é Inquiry. Nesta aprendizagem, como é referida em diversos trabalhos da área, a construção de conhecimento se dá através da resolução de problemas, que envolve observações, elaboração de questões e hipóteses, consulta a fontes de informação, planejamento e execução de planos, coleta, análise e interpretação de dados, proposição de explicações, compartilhamento de informações (HOFSTEIN; LUNETTA, 2004).

Em qualquer nível de ensino, são inúmeros os desafios para compreender e desenvolver o ensino investigativo de química em sala de aula, diversificando as práticas comumente realizadas no cotidiano escolar. Tal estratégia engloba quaisquer atividades que basicamente centradas no aluno, possibilitam o desenvolvimento da autonomia e da capacidade de tomar decisões, de avaliar e de resolver problemas, apropriando-se de conceitos e teorias das Ciências.

Quando se fala de ensino de Ciências por investigação, está se falando de estratégias de ensino diferentes das que têm sido mais frequentemente utilizadas nas escolas. A atividade de caráter investigativo é uma estratégia, entre outras, que o professor utiliza para diversificar sua prática no cotidiano escolar. Tal estratégia engloba quaisquer atividades que, basicamente centradas no aluno, possibilitam o desenvolvimento da autonomia e da capacidade de tomar decisões, de avaliar e de resolver problemas, apropriando-se de conceitos e teorias das Ciências da natureza (CASTRO, 2008).

Desta forma, as atividades de caráter investigativo implicam, inicialmente, a proposição de situações-problemas, que então orientam e acompanham todo o processo de 
investigação. Nesse contexto o professor desempenha o papel de guia e de orientador das atividades - é ele quem propõe e discute questões, contribui para o planejamento da investigação dos alunos, orienta o levantamento de evidências e explicações teóricas, possibilita a discussão e a argumentação entre os estudantes, introduz conceitos e promove a sistematização do conhecimento. Consequentemente, o professor oportuniza, de forma significativa, a vivência de experiências pelos estudantes, permitindo-lhes assim, a construção de novos conhecimentos acerca do que está sendo investigado.

$\mathrm{Na}$ resolução de problemas, ao qual se propõe o ensino investigativo, deve-se observar se os alunos colaboram entre si na busca da solução de problema, se apresentam comportamento que indica uma aprendizagem atitudinal, e se eles discutem, buscando ideias que servirão de hipóteses e as testam. É preciso verificar quem não se desenvolve nem em termos de atitude nem em termos de processo.

No ensino por investigação, os professores colocam os alunos em situações de realizar pequenas pesquisas, combinando simultaneamente conteúdos conceituais, procedimentais e atitudinais (POZO, 1998). Essa abordagem também possibilita que o aluno desenvolva, exercite ou coloquem em ação as três categorias de conteúdos procedimentais (Pro, 1998): habilidades de investigar, manipular e comunicar. Com relação ao comunicar, Gil-Perez (1996) enfatiza que não se trata de olhar para os alunos como cientistas profissionais, isso significa que o professor deve considerar a importância de colocar os alunos frente a situações-problema adequadas, proporcionando a construção do próprio conhecimento por meio de uma orientação sócio-construtivista que visa à promoção da aprendizagem significativa em ciências.

Para os autores, numa discussão aberta, professor/classe, os comportamentos que indicam uma aprendizagem atitudinal são, por exemplo, esperar a sua vez para falar ou prestar atenção e considerar a fala do colega. Comportamentos relacionados ao domínio procedimental podem ser observados quando o aluno descreve as ações observadas; relaciona causas e efeito, explica o fenômeno observado. Tendo em vista que a aprendizagem por investigação não é uma estratégia simples de ser utilizada, pois envolve conhecimentos e habilidades diversos, que não são facilmente encontradas nos livros didáticos como os conteúdos curriculares.

Neste contexto, no processo de avaliação tradicional, não se considera como determinantes para os conhecimentos a serem construídos, a aproximação, a captação e a internalização do conhecimento novo. A ideia de ensino por recepção passiva pressupõe um processo causal, se reduzindo a estudar o material indicado, para fixação. Nesta ótica se valoriza os conteúdos curriculares 


\section{Research, Society and Development, v. 7, n. 5, p. 01-18, e1275317, 2018}

ISSN 2525-3409 (CC BY 4.0)

e conceituais, onde não se precisa considerar o processo, mas apenas, o resultado, diminuído as demais aprendizagens (DANTAS; MASSONI; SANTOS, 2017).

Neste sentido, é bastante razoável supor que o futuro professor, aprendendo em sua formação inicial os conteúdos químicos por meio da investigação, tenha maior facilidade de aplicar esse procedimento didático em seu trabalho docente, considerando, contudo de acordo com Carvalho et al. (2004), uma atividade investigativa não pode se reduzir a uma mera observação ou manipulação de dados - ela deve levar ao aluno a refletir, a discutir, a explicar e a relatar seu trabalho aos colegas.

Em vista disso, e com o objetivo de explorar as potencialidades das atividades investigativas na formação de professores, foi analisada uma experiência de ensino na perspectiva investigativa. O trabalho tinha ainda como objetivo propiciar que os alunos recuperassem os conceitos acerca de concepções de ciências, assim como permitir que eles vivenciassem uma nova estratégia de ensino para que pudessem, enquanto futuros profissionais, trabalhar atividades investigativas com seus alunos.

\section{Formação Inicial e o Ensino investigativo}

No discurso teórico da formação como espaço de análise, Vaillant et al. (2012) falam de três tendências contrapostas em relação ao conceito de formação. A primeira afirma que é impossível utilizar este conceito de linguagem técnica em educação, devido, fundamentalmente, à tradição filosófica que o sustenta.

Uma segunda tendência recorre ao conceito formação para identificar múltiplos e, às vezes, contraditórios fenômenos. Assim, a formação não se limita como conceito, a um campo especificamente profissional, mas sim se refere a diversas dimensões. A terceira tendência afirma que na atualidade não há sentido eliminar o conceito formação, pois a "formação não é nem um conceito geral que abarca a educação e o ensino, nem tampouco está subordinada a eles" (p. 269).

Existe uma considerável polissemia de termos para referir-se aos processos pelos quais as pessoas adultas individualmente ou em grupo iniciam um processo de aprendizagem.

Berbaum (1992) propõe a respeito disso que:

Uma ação de formação corresponde a um conjunto de condutas, de interações entre formadores e educandos, que pode perseguir múltiplas finalidades, explicitadas ou não, e através das quais se chega a certa mudanças (BERBAUM, 1982; In: VAILLANT et al. 2012, p. 28). 
A discussão sobre a formação de professores nas universidades, suscitada pelas alterações na estrutura jurídico-legal da educação brasileira e, por conseguinte, pelas mudanças na escola básica e no ensino superior, parecem caminhar na direção da formulação de um projeto político-pedagógico para as licenciaturas que consiga efetivamente romper com o modelo que continua subjacente aos cursos de formação docente no país (PEREIRA, 1999).

O licenciado em química deve estar consciente dos aspectos que definem a realidade educacional, sendo capaz de identificar o processo de ensino e aprendizagem como processo humano em construção. Este profissional deve possuir formação humanística que lhe permita exercer plenamente sua cidadania e, no exercício de sua docência, saber respeitar o direito à vida e ao bem estar dos cidadãos.

Este parecer estabelece, também, em relação ao ensino de química, que o licenciado em química deve saber trabalhar em laboratório e saber usar a experimentação em química como recurso didático (CNE/CES, 2001). Assim, as concepções desses professores sobre o processo ensino e aprendizagem, bem como a evolução dessas concepções ao longo do curso de formação inicial, são de grande importância na sua prática docente.

A pertinência de temas de investigação para uma melhor formação e atuação docente em Química decorre da constatação de que a prática pedagógica de cada professor(a) manifesta suas concepções de ensino, aprendizagem e de conhecimento, como também suas crenças, seus sentimentos, seus compromissos políticos e sociais (ARAGÃO, 2000).

Há críticas sobre as metodologias e os conteúdos trabalhados na química nos dias de hoje, pois frente à complexidade do mundo atual, não é mais concebível na atualidade, que os docentes, tanto em nível básico quanto em nível superior, trabalhem de forma isolada em seus saberes e práticas. No entanto, a maior parte dos cursos de formação de professores e mesmo as disciplinas em seu interior não tem possibilitado este entrosamento. As reformulações propostas na estrutura e nos objetivos da educação básica têm consequências importantes sobre a necessidade de repensar a formação inicial de professores (BRASIL, 2006).

De acordo com essa legislação, o futuro professor tem que ter contato com aluno durante todo o processo de formação, com atitudes, modelos didáticos e modos de organização que se pretende que venham a ser concretizados nas suas práticas pedagógicas (BRASIL, 2002). Uma das estratégias referendadas nas Diretrizes Curriculares Nacionais para a formação inicial de professores é a resolução de problemas.

Com a vigência das atuais Diretrizes Curriculares Nacionais para a formação inicial de professores, percebe-se que o professor passou a ser visto como o mediador na discussão 
de significados para a construção do conhecimento. Tendo de elaborar e atuar em projetos pedagógicos que valorizem o desenvolvimento de competências, a interdisciplinaridade, a contextualização do ensino e a preparação dos alunos para o exercício da cidadania (BRASIL, 2002).

Para Carvalho et al. (2004) o papel do professor na aprendizagem por investigação são múltiplos. Implica inicialmente a proposição de situações-problemas, levando em consideração os conhecimentos prévios dos alunos, que então orientam e acompanham todo o processo de investigação.

Nesse contexto o professor desempenha a função de guia e de orientador das atividades, é ele quem propõe e discute questões, contribui para o planejamento da investigação dos alunos, orienta o levantamento de evidências e explicações teóricas, possibilita as discussões e a argumentação entre estudantes, introduz conceitos e promove a sistematização do conhecimento. Consequentemente, o professor oportuniza, de forma significativa, a vivência de experiências pelos estudantes, permitindo-lhes assim, a construção de novos conhecimentos do que está sendo investigado.

Um dos principais obstáculos encontrados pelos professores da escola básica é que estes não aprenderam a elaborar atividades que envolvam situações problemáticas (GILPÉREZ et al., 1999). Pesquisas sobre experiências na formação de professores apontam a existência de diferenças marcantes entre o objetivo perseguido pelos estruturadores dos currículos e a prática docente que é efetuada em sala de aula. Estas discrepâncias podem estar atreladas às crenças sobre ensino e aprendizagem que estes professores possuem (CARVALHO; GIL-PÉREZ, 2006).

Para Marcelo e Vaillant (2012) o que ocorre nos sistemas educacionais repercute profundamente na vida dos indivíduos e nas futuras gerações. E, no entanto, os processos de projeto e formulação de políticas educativas tratam apenas de solucionar questões bastante imediatas ou de encontrar modos mais eficazes para manter a prática estabelecida, em lugar de pensar a longo prazo. Os processos de mudança social e educativa transformarão - sem dúvida alguma - ainda mais o trabalho dos professores, sua formação e também a valorização que a sociedade faz de seu trabalho.

Trabalhar a investigação na formação de professores pode fornecer a esses profissionais uma nova linha de trabalho, mostrando novas estratégias de atuação que permitam um ensino mais participativo e criativo. E por isso, proporcionar investigações na formação inicial deve ser uma tarefa constante do professor 
Research, Society and Development, v. 7, n. 5, p. 01-18, e1275317, 2018

ISSN 2525-3409 (CC BY 4.0)

Portanto, uma prática que aborde investigações na formação de professores pode adquirir diferentes significados e interpretações, de acordo com o contexto no qual será realizada. Logo, atividades investigativas podem ser utilizadas em qualquer nível de ensino (FERREIRA, 2006).

Entender e conhecer as concepções sobre ensino investigativo de ciências/Química e a história de alguns conceitos dentro de seus aspectos históricos menos restrita a dados bibliográficos ou curiosidades da vida dos cientistas permite como, diz Bachelard (2007), geometrizar e ter maior abstração sobre a ciência. Concordamos com Bybee (2000) que a ideia do ensino de ciência como investigação possui uma longa história na educação científica e é uma história de confusão entre o significado de ensinar ciência por investigação e sobre sua implementação em sala.

A abordagem ao ensino de Ciências por investigação ainda não está bem estabelecida no Brasil. Existem poucos artigos publicados sobre o tema (SÁ, et al, 2007). Isto se deve ao fato de que o ensino por investigação começou a ser debatido amplamente apenas após os PCN (1998) e da publicação dos documentos que orientaram a reforma da educação em Ciências nos Estados Unidos.

Rodrigues e Borges (2008, p 10) afirmam que:

sobre o ensino por investigação no século XX, o documento Project 2061 Science For All Americans (AAAS, 1989), que foi uma tentativa de explicitar o consenso sobre o que os estudantes deveriam saber para serem cientificamente alfabetizados num sentido amplo. Os autores do projeto recomendavam que o ensino de ciência devesse ser consistente com a natureza da investigação cientifica e que os estudantes deveriam estar a par das coisas ao seu redor como dispositivos, organismos, materiais, formas observando-os, coletando, manipulando, descrevendo-os, fazendo perguntas, discutindo e tentando encontrar respostas para suas perguntas. Adotando uma linha semelhante, a National Research Council (NRC) contribuiu com a definição de alfabetização científica através da publicação do National Science Education Standards (NRC, 1996, p. 10).

Os autores colocam um aspecto em que essa forma de pensamento de certa forma representa certa resistência, na qual o processo de investigação da natureza é demarcado por um método científico único e universal respaldado pela obtenção de dados empíricos e pela indução dentro de uma visão da ciência cumulativa.

Por outro lado, evidenciam a importância de atividades investigativas no ensino de ciências/Química, pois parece não haver preocupação dos professores da área em mudanças de paradigmas ou de conceitos no ensino empirista-positivista, capaz de ser substituída por outra que abarque o maior número de dados empíricos, bem como discussões nos campos da 
filosofia, sociologia e história da ciência sobre o processo de desenvolvimento do conhecimento científico.

No entanto, o que ainda vivencia-se nos cursos de formação inicial de professores de ciências é um ensino fragmentado, com aulas teóricas separadas das práticas. De forma semelhante, a didática das ciências e o conhecimento pedagógico estão apartados dos conhecimentos específicos (SILVA, et. al., 2010; PASSOS; DEL PINO, 2009; SCHNETZLER, 2002; CARVALHO; GIL-PÉREZ, 2006).

Desta forma Silva et al (2010) um dos problemas relacionados à qualidade do ensino de Ciências é a ausência de experimentação. Esta ausência está relacionada às crenças frequentemente veiculadas no meio educacional. Os documentos oficiais recentes para o ensino de Ciências/Química (Parâmetros Curriculares Nacionais - PCN; Orientações Curriculares Nacionais - OCN; Orientações Educacionais Complementares aos Parâmetros Curriculares Nacionais - PCN+ recomendam o uso da experimentação, enfatizando a relação teoria-aprendizagem, incorporando a interdisciplinaridade e a contextualização.

Neste sentido, acreditamos já na formação inicial, há a necessidade de se modificar drasticamente o que se entende por laboratório. Esse novo olhar sobre o ensino proporciona uma visão mais ampla dos fenômenos, revelando a complexidade da vida moderna e possibilitando a diversidade de abordagens investigativas. O termo Laboratório vem do francês antigo "laboratoire", que por sua vez, vem do latim medieval "laboratorium", de "labore" que quer dizer trabalhar, local onde se fazem experiências (FERREIRA, 2008).

Pode-se concluir, que o termo laboratório está associado a um "lugar específico". A atual concepção de laboratório, enquanto um espaço isolado da sala de aula comum é um conceito antigo que prevalece até os dias atuais. Transmitindo conforme Cortés e De La Gándara (2007) uma visão deformada da ciência e não estimula os licenciandos a elaborarem atividades investigativas em seus futuros planos de ensino.

Na realidade, não deveria haver distinção entre sala de aula e laboratório, uma vez que diante de um problema, o estudante deve fazer mais do que simples observações e medidas experimentais, pois as possíveis hipóteses por eles criadas, na tentativa de solucionar o problema, deveriam ser discutidas com o objetivo de se avaliar a pertinência, a viabilidade e, se for o caso, propor procedimentos que possam verificar as diferentes propostas de solução. Nessa perspectiva, a teoria e a prática passam a ser vistas como um processo único que possibilita a aprendizagem de conceitos científicos (SILVA, 2010).

Concordamos com Silva e Zanon (2000) quando afirmam que o ponto primordial da ausência da atividade investigativa está na formação docente e não apenas na falta de 
infraestrutura. Acreditamos que de nada adiantará um laboratório bem estruturado se os docentes continuarem com uma visão simplista no ensino de química, considerando como funções exclusivas da docência em química comprovar leis e teorias, motivar o aluno e desenvolver habilidades técnicas ou laboratoriais.

Um aspecto positivo da utilização das atividades investigativas é que elas podem ser inseridas nas aulas teóricas, à medida que o professor desenvolve o programa de ensino de uma determinada série. Essa estratégia pode minimizar a desarticulação entre as aulas teóricas e aulas de laboratório.

Carvalho (1998) afirma que não se pode negar que há docentes que desenvolvem estratégias de ensino, em suas aulas, mais dinâmicas voltadas para a prática, para a construção de conhecimento, realizando atividades com vistas a uma real aprendizagem. Percebe-se que a prática docente é permeada de saberes pouco prático e sem significados.

Sobre as atividades investigativas no Brasil, de acordo com Munford e Lima (2008, p. 4), coloca que essa abordagem está menos consagrada e é relativamente pouco discutida. Mesmo assim, o interesse vem crescendo, sendo que pesquisadores e educadores voltam-se para a questão. .

No entanto, de acordo com Mizukami, et. al. (2002) pode-se dizer que há uma nova vertente denominada racionalidade prática, que aponta para outra forma de entender a formação, já que o modelo da racionalidade técnica é insuficiente para atender às necessidades da prática docente. Assim, a racionalidade prática compreende que a formação é um continuum e tem como embasamento teórico a concepção construtivista.

Visando incorporar uma práxis docente por ensino investigativo nas Instituições de Ensino Superior, faz-se necessário uma profunda transformação nos procedimentos didáticos dos formadores de professores. A construção do conhecimento científico tem exigências metodológicas e epistemológicas que serão atendidas quando o professor formador assumir o papel de investigador e orientador, capaz de dirigir as investigações dos licenciandos, investigadores novatos.

Com esta dinâmica de aula, os futuros professores poderão assumir a postura de orientador e não apenas a de transmissores de conhecimento, como tem sido frequentemente vivenciado na maioria das salas de aula de química (PASSOS; SANTOS, 2013).

Ressaltamos que na formação inicial, independente dos modelos de formação da América Latina os professores devem ensinar e devem aprender a ensinar, possibilitando a criação de um ambiente propício para o aprendiz, buscando uma cultura colaborativa formando uma comunidade entre seus pares. O ensino investigativo não representa a solução 
Research, Society and Development, v. 7, n. 5, p. 01-18, e1275317, 2018

ISSN 2525-3409 (CC BY 4.0)

dos problemas na educação química e para além de uma estratégia ou metodologia a docência deve ter a investigação incorporada nas concepções epistemológica dos professores.

\section{Estratégia utilizada na Formação inicial}

Apresenta-se neste trabalho uma investigação sobre estratégia de ensino investigativo na formação de professores de química em uma Universidade pública federal do Estado de São Paulo, em duas turmas, com um professor e sete alunos da licenciatura em química através da disciplina Ensino e Experimentação em Química, durante um quadrimestre de 2013.

A escolha da disciplina deveu-se como parte de uma pesquisa sobre orientação num programa Scrito Senso de uma universidade pública do Estado de São Paulo, como base necessária para o aprofundamento de referenciais teóricos e do desenvolvimento dos instrumentos de pesquisa. A metodologia no estudo é de natureza qualitativa (Collado; Sampiere, 2014) do tipo análise do discurso (BARDIN, 2011).

Os dados são compostos pela análise da práxis do plano de aula docente na disciplina Experimentação e Ensino de Química. A investigação objetivou explorar as potencialidades das atividades investigativas na formação de professores, analisando uma experiência de ensino na perspectiva investigativa na licenciatura em química.

\section{Planejamento de Ensino do Professor}

O planejamento de atividade de natureza investigativa, diante de nossa realidade educacional, representa uma mudança significativa na postura do professor e também do aluno, e consequentemente, na dinâmica das interações na sala de aula. O professor é peça fundamental em qualquer processo de mudança que envolve a sala de aula. Nesse sentido, segundo Carvalho (2006), se não houver uma vontade deliberada de aceitação e aplicação de novas propostas de ensino, nenhuma educativa formal poderá ser efetivada com sucesso.

Para a realização do trabalho docente, e para propiciar a discussão entre os alunos, observou-se a disciplina Experimentação e Ensino de Química, que é obrigatória para o curso de licenciatura em química na Instituição de Ensino Superior, através de duas turmas em turnos matutino e noturno. Foram aulas com duração de três horas em cada turma uma vez por semana durante um quadrimestre, com três alunos no turno da manhã e quatro alunos no 
turno da noite no laboratório. A escolha desse local se deu pelo fato de mostrar outro conceito de sala de aula dentro do que preconiza as atividades investigativas.

O objetivo do professor com as turmas foi o de fornecer aos licenciandos subsídios para que pudesse refletir mais profundamente acerca do papel da experimentação no ensino de Ciências/Química e mais especificamente analisar criticamente o papel da experimentação no ensino de Química; discutir como alguns documentos oficiais da educação no país abordam a experimentação no ensino de Ciências/Química; elaborar detalhadamente um roteiro de aula experimental investigativa para o ensino médio considerando um conteúdo químico e o contexto da escola onde a mesma seria desenvolvida; ministrar a aula experimental preparada em uma sala de aula; e avaliar criticamente as aulas ministradas a partir das discussões realizadas durante toda a disciplina.

O pressuposto metodológico de ensino do professor foi ministrado através de atividades teóricas-práticas constando de grupos de discussão, exposição oral, elaboração e apresentação de aulas experimentais pelos alunos com registro de áudio e vídeo das mesmas. O processo avaliativo se propunha ser realizado através do acompanhamento contínuo do desempenho do aluno considerando sua autonomia, responsabilidade, criticidade, especialmente por intermédio da participação nas discussões e realização das atividades propostas. Neste sentido preconizou-se a auto avaliação contínua com os alunos.

Planejar o ensino investigativo não é uma tarefa fácil. Além dos conhecimentos desejáveis que o professor deveria ter para promover o ensino nesta perspectiva a formalização de um procedimento de ensino não reduz a complexidade de planejar, aponta-se que o professor para construir seu ensino, deve dispor de propostas e critérios e estratégias que dirijam e fundamentem suas reflexões e tomada de decisões (SÁNCHEZ-BLANCO; VARCÁCEL-PÉREZ, 2000).

Neste sentido, propõem um conjunto de ações que poderiam auxiliar o professor e seu planejamento de ensino. São elas: analisar e selecionar o conteúdo, apontar as possíveis dificuldades de aprendizagem desses conteúdos, considerando as ideias prévias dos alunos e as exigências cognitivas, selecionar os objetivos de ensino e de aprendizagem e estabelecer as implicações da sequencia e das estratégias escolhidas para o ensino.

No Quadro 1, o cronograma de atividades da disciplina apresentado pelo professor da disciplina:

Quadro 1: Cronograma docente de atividade da disciplina 
ISSN 2525-3409 (CC BY 4.0)

\begin{tabular}{|c|l|}
\hline AULA & \multicolumn{1}{|c|}{ PROGRAMAÇAO } \\
\hline 1 & $\begin{array}{l}\text { Apresentação da disciplina e questionário de ideias prévias sobre os conteúdos } \\
\text { da disciplina. }\end{array}$ \\
\hline 2 & $\begin{array}{l}\text { Grupo de discussão sobre os textos: "A natureza das atividades experimentais } \\
\text { no ensino de ciências um programa de pesquisa educativa nos cursos de } \\
\text { licenciatura" e "Ensino experimental de química: uma abordagem investigativa } \\
\text { contextualizada". }\end{array}$ \\
\hline 3 & $\begin{array}{l}\text { Grupo de discussão sobre os textos: "Experimentar sem medo de errar" e/ou } \\
\text { "Experimentação no ensino de química: caminhos e descaminhos rumo à } \\
\text { aprendizagem significativa". }\end{array}$ \\
\hline 4 & Os PCNEM e a Experimentação. \\
\hline 5 & Escolha dos conteúdos químicos e proposição dos experimentos pelos grupos. \\
\hline 6 & Elaboração e testagem dos experimentos pelos grupos \\
\hline 7 & Apresentação dos experimentos pelos grupos. \\
\hline 8 & Auto avaliação da aula experimental. \\
\hline 9 & Avaliação da disciplina \\
\hline
\end{tabular}

Fonte: Ementa da disciplina EEQ.

Tendo em vista o desenvolvimento do ensino investigativo como estratégia de ensino, como é proposto neste trabalho, consideramos que o professor pode adquirir formação para saber propor situações e formular perguntas que possam mobilizar os conhecimentos prévios dos alunos, que provoquem interações dialógicas entre eles e o professor e que oriente a interpretação dos dados obtidos nas atividades e a construção do conhecimento científico.

Os textos foram todos disponibilizados antecipadamente aos correios eletrônicos dos alunos. Priorizou-se até a aula 3 a interação dialógica mais intensa colocando-se uma questão problema inicial, na qual os alunos eram estimulados a colocarem seus argumentos, na aula 4 o professor embora tenha assumido uma característica tradicional se permitiu ao final da aula as discussões dialógicas e a percepção de diferenças entre as duas posturas de aula.

Os alunos tiveram total liberdade no período de quatro aulas em escolher os conteúdos químico e proposições de experimento, a sala/laboratório ficou disponibilizada para testagem dos experimentos, bem como materiais necessários para as mesmas acompanhados de um observador da disciplina e monitor de laboratório. O professor se disponibilizou a qualquer momento atender aos alunos.

Os temas escolhidos pelos alunos contemplaram os conteúdos curriculares buscandose relacionar com realidades de diferentes escolas e Ciências, Tecnologia, Sociedade e Ambiente (CTSA) e as aulas dialógicas baseadas nos textos disponibilizados e discutidos. As apresentações foram organizadas em dois dias para todas as sete propostas de aula. Após todas as apresentações que foram filmadas e disponibilizadas aos alunos, se fez uma auto avaliação das aulas experimentais investigativas e a posterior a avaliação da disciplina.

Todas as propostas dos licenciandos partiram de situações problemas. Neste sentido Mayer (1981) e Pozo (1998) definem que os problemas podem ser mal ou bem definidos. 
Problema mal definido permite encontrar várias soluções, pois o ponto de partida e os meios não são bem identificados. Além disso, nos problemas definidos como mal estruturados é possível encontrar várias soluções diferentes entre si, todas elas válidas como forma de resolver o problema por meio de métodos também diferentes e igualmente válidos.

Enquanto que o Problema bem definido é aquele em que facilmente podemos identificar quando a solução foi alcançada. Neste tipo de trabalho tanto o ponto de partida do problema (proposição), como o ponto de chegada (solução) e o tipo de intervenções que devem ser feitas para percorrer a distância entre ambos estão explicitados de forma muito clara.

A análise dos trabalhos observados torna claro que as atividades diferenciadas são atrativas para o envolvimento e participação dos alunos, igualmente estas são muito diferentes das que comumente estão habituados a realizar nas aulas tradicionais. Verificando-se que independente da falta de hábito de experiências investigativas acaba se superando no decorrer disciplina quando bem orientados.

Quanto à contribuição a formação docente no ensino de química, os licenciandos demonstraram que a experiência da utilização da estratégia investigativa na formação inicial é motivadora. Vivências diferenciadas são fundamentais na formação, pois são metodologias didáticas que possuem potencial para envolver e mudar a rotina dos alunos.

\section{Desafios para a Formação Química em perspectiva do ensino investigativo}

Existem múltiplas estratégias para facilitar a análise sobre as concepções prévias do ensino. Essas são essenciais na melhoria das capacidades docentes e na aquisição de aprendizagem adequadas ao estudante (VAILLANT, et al. 2012).

Neste sentido, as concepções de ensino de professores são determinantes na forma como pensam e agem, sendo percepcionadas pelos investigadores educacionais como guias dos professores, quer das decisões curriculares que tornam, quer das ações que desenvolvem na sua prática.

É importante que o professor tenha claro desde o início de sua formação acadêmica que o ensino de química não se trata de um ensino transmissivo em que irá repetir o uso de atividades experimentais exatamente como aprendeu. É necessário que este professor reflita, elabore e utilize estratégia no uso da experimentação de maneira a desenvolver as capacidades científicas dos seus alunos. 
Porlán (1998) ainda coloca que é necessário levar em consideração às concepções pedagógicas destes docentes, visto que estas constituem suas reais concepções sobre o conhecimento e que poderá influenciar em suas intervenções práticas. É necessário identificar os seus padrões de evolução para que os processos formativos permitam o seu desenvolvimento crítico e autônomo. Concorda-se com Silva e Zanon (2000) quando afirmam que o ponto primordial da ausência da experimentação está na formação docente e não apenas na falta de infraestrutura.

Acredita-se que a metodologia utilizada pelo docente na condução de trabalho traz, mesmo que implicitamente, características da natureza da ciência. Ao conduzir situações de aprendizagem, ao criar um ambiente propício para o ensino, também se ensina sobre Ciências e não apenas sobre aspectos conceituais. Uma metodologia investigativa, por exemplo, pode ressaltar o caráter investigativo do conhecimento científico, além de outros aspectos. Portando, a metodologia de trabalho não é neutra, o método de trabalho utilizado pelo docente também é conteúdo (BRICCIA, 2013).

Para essa leitura do mundo, é preciso que se desenvolvam também habilidades e competências de identificar fontes de informação e de formas para obter informações relevantes em Química, sabendo interpretá-las não só nos seus aspectos químicos, mas considerando também as implicações sociopolíticas, culturais e econômicas. Para dar conta de tais interpretações, são necessárias competências e habilidades de reconhecer os limites éticos e morais do conhecimento científico, tecnológico e das suas relações (BRASIL, 1996).

O ensino investigativo tem por objetivo discutir aspectos importantes do ensino e da aprendizagem dos conteúdos científicos, suas estratégias, fundamentos teóricos e as ações do professor em conduzi-las, propiciando elementos para que reflita sobre suas próprias aulas e elabore seus planos de trabalho (CARVALHO, 2013).

Neste sentido as estratégias de ensino investigativa que como afirma Chassot (2003) podem estar ligada ao fato dos próprios professores possuírem pré-concepções devido às suas experiências acadêmicas, É imprescindível buscar formas realistas e exequíveis, dentro do quadro presente, para aperfeiçoar o ensino investigativo da química, possibilitando a construção de uma melhor concepção de ensino de química.

Identificamos que a análise de estratégias no ensino investigativo de química, segundo nosso juízo, focalizam os aspectos centrais dessa problemática, que dizem respeito à carência na formação e concepções dos professores e à falta de clareza sobre o papel da experimentação na aprendizagem. 
Research, Society and Development, v. 7, n. 5, p. 01-18, e1275317, 2018

ISSN 2525-3409 (CC BY 4.0)

Guimarães (2009) ressalta que, a formação inicial do professor não lhe oferece condições suficientes para fazer intervenções com qualidade em sua área. Reforçando esta perspectiva, acredita-se que a prática atual da experiência formativa do professor é um processo que possui efeito direto na realidade cotidiana das escolas.

O que reforça Cachapuz (2002) para que as atitudes dos professores sofram mudanças, é fundamental que estes observem a ineficácia e o insucesso das mesmas e disponham de uma nova orientação que lhes ofereça vantagens e esteja em sintonia com os seus objetivos pessoais.

\section{Considerações finais}

O papel do professor formador na elaboração de estratégias mediadas por atividades investigativas na formação inicial de professores em química é de grande importância, principalmente para melhorar as concepções cientificas, superando crenças e obstáculos comumente manifestados pelos que se aventuram na educação química. Pode-se verificar que a implementação da estratégia de aulas dialogadas contribui significativamente para aprendizagem dos estudantes e suas concepções científicas.

O ensino por investigação na educação química apresenta um diferencial, frente a outras estratégias já conhecidas voltadas ao Ensino de Química, pois possui elementos muito valiosos no processo de apropriação do conhecimento, e supera métodos didáticos difundidos que não aproximam o estudante da realidade e o distancia da compreensão dos conteúdos conceituais, procedimentais e atitudinais.

Finalmente, a partir das reflexões neste trabalho, pode-se considera que a introdução de atividades investigativas no cotidiano escolar e principalmente na formação inicial é muito importante, devido à influência que os mesmos exercem frente aos alunos, pois quando eles estão envolvidos, emocionalmente, na ação, torna-se mais fácil e dinâmico o processo de ensino e aprendizagem.

\section{Referências}

BACHELARD, G. A Formação do Espírito Científico. Tradução de Estela dos Santos Abreu. Rio de Janeiro, Contratempo, 1996 (2007).

BARDIN, L. Análise de conteúdo. São Paulo: Edições 70, 2011, 229 p. 
BYBEE, R. W. Teaching Science as Inquiry. Inquiring into Inquiry Learning and Teaching in Science. (J. Minstrell \& Emily H. van Zee, eds.) p. 20-46. AAAS, Washington, DC, 2000.

BERBAUM, J. Etude systemique des actions de formation. Paris: Presses Universitaries de France, 1982.

BRASIL., Ministério da Educação e Desporto. Parâmetros Curriculares Nacional (PCN+): Ensino Médio: Ciências da natureza, Matemática e Tecnologias. Brasilia. 2002.

.Ministério da Educação, Secretaria de Educação Básica. Orientações curriculares para o ensino médio - Ciências da Natureza, Matemática e suas Tecnologias. Brasília, v. 2, 2006. 135 p.

BRICCIA, V. Sobre a natureza da Ciência e o ensino. In: Ensino de Ciências por investigação: condições para implementação em sala de aula. Ana Maria Pessoa de Carvalho, (org.). - São Paulo: cengage learning, 2013.

CACHAPUZ, A. F. - A Universidade e a Valorização do Ensino e a Formação de seus Docentes. In: MACIEE, Lizete S. B. Reflexões sobre a formação de professores Campinas, SP; Papirus, 2002 - (Coleção Magistério: Formação e Trabalho Pedagógico).

CARvalho, A. M. P., et al. Ensino de Ciências: unindo a pesquisa e a prática. São Paulo: Editora Thompson, 2004.

; GIL-PÉREZ, D. Formação de Professores de Ciências: tendências e inovações. São Paulo: Cortez, 2006. 120p.

.Critérios estruturantes para o ensino de Ciências. In: Carvalho, A.M.P.(org). Ensino de ciências: unindo a pesquisa e a prática. São Paulo: Pioneira Thompson Learning, 1998.

.O Ensino de Ciências por investigação: condições para implementação em sala de aula. Ana Maria Pessoa de Carvalho, (org.). - São Paulo: cengage learning, 2013.

CASTRO, M. E. C.; MARTINS, C. M. C.; MUNFORD, D. Ensino de Ciências por investigação - ENCI: módulo / Belo Horizonte - UFMG, 2008.

CHASSOT, A. Alfabetização Científica: questões e desafios para a educação. 3.ed. Ijuí: Ed. Unijuí, 2003. 440p. - (Coleção educação em química).

COLLADO, C. F.; SAMPÍERI, R. H. Medologia de la investigacion. Mcgraw-Hill. $5^{\mathrm{a} e d .}$ 656 p. 2014. 
CORTÉS GRACIA, A. L.; DE LA GÁNDARA GÓMEZ, Milagros. La construcción de problemas em el laboratorio durante la formación del profesorado: uma experiência didáctica. Enseñanza de las Ciencias, v. 25, n.3, p. 435-450, nov, 2007.

DANTAS, C. R. S.; MASSONI, N. T.; SANTOS, F. M. T. A avaliação no Ensino de Ciências Naturais nos documentos oficiais e na literatura acadêmica: uma temática com muitas questões em aberto. Ensaio: aval. pol. públ. Educ., Rio de Janeiro. 2017.

FERREIRA, L. H.; HARTWIG, D. R. Experimentação. Coordenação do GT 2 no I Encontro Paulista de Pesquisa em Ensino de Química, 2004. (on line) Disponível em <gpquae.iqm.unicamp.br/EPPEQ.pdf>. Acesso em 14 de Abril 2008.

GIL-PÉREZ, D.; et al. Tiene sentido seguir distinguiendo entre aprendizaje de conceptos, resolución de problemas de lapiz y papel y realización de practicas de laboratório? Enseñanza de las Ciencias, v. 17, n. 2, p. 311-320, jun,1999.

. Newtrends in science education. International Journal of Science Education. 18(8), p.888-901, 1996.

GUIMARÃES, C. C. Experimentação no Ensino de Química: Caminhos e Descaminhos Rumo à Aprendizagem Significativa. Química Nova na Escola, v.31, n³, 2009.

HOFSTEIN, A.; LUNETTA, V. N. Laboratory in science education: Foundations for the twenty-first century. Science Education, v.88, n.1, p. 28-54, 2004.

MUNFORD, D.; LIMA, M. E. C. de C. Ensinar ciências por investigação: em quê estamos de acordo? Revista Ensaio, v. 1, 2008.

MIZUKAMI, M. G. N. et. al. Escola e aprendizagem da docência: processos de investigação e formação. São Carlos, EDUFSCar. 2002.

PEREIRA, J.E.D. As licenciaturas e as novas políticas educacionais para a formação docente. Campinas,1999, vol 20, n.68, Disponível em: http://www.scielo.br/scielo.php?script=sci_arttext\&pid=S0101-73301999000300006, acesso em 30 de fev de 2014.

PÓRLAN, R.; RIVERO, A. El conocimiento de los professors: Uma propuesta formativa en al área de ciências: Sevilla: Diada Editora, 1998.

POZO, J.I. (Org.). A solução de problemas. Porto Alegre. Artmed, 1998.

PRO, A.; Se pueden ensinar contenidos procedimentais en las classes de ciencias? Enseñanza de las Ciencias, 16(1), 21-41, 1998. 
RODRIGUES, B. A.; BORGES, A. T. O Ensino de Ciências por Investigação: Reconstrução Histórica. XI Encontro de Pesquisa em Ensino de Física - Curitiba - 2008.

SÁ. E. F. de; PAUlA, H. de F.; LiMA, M. E. C. de C. e AGUiAR, O. G. de. As Características das Atividades Investigativas Segundo Tutores e Coordenadores de um Curso de Especialização em Ensino de Ciências. In: ENPEC - Encontro Nacional de Pesquisa em Ensino de Ciências, 6, Florianópolis, SC, Atas... SBF, 2007.

SÁNCHEZ-BLANCO, G.; VARCEL-PÉREZ, M. V. Qué tienen em cuenta los professores cuando sellecionan el contenido de enseñanza? Cambios y dificutades tras um programa de formación. Enseñanza de las Ciências, v.18, n.3, p.423-437, 2000.

SILVA, R.R.; MACHADO, P.F.L.; TUNES, E. Experimentar Sem Medo de Errar. Cap. 9, p. 231-261. In: Ensino de Química em Foco. Org. SANTOS, W. L.; MALDANER, O.A., Ed. Unijuí. 2010.

SILVA, L. H. A.; ZANON, L.B. A Experimentação no ensino de Ciências. In: SCHNETZLER, R, P; ARAGÃO, R.M.R (Org). Ensino de Ciências: fundamentos de abordagens. Piracicaba:Capes/Unimep. Cap. 6. 2000.

SILVA, L. H. A.; ZANON, L.B. A Experimentação no ensino de Ciências. In: SCHNETZLER, R. A Pesquisa em Ensino de Química no Brasil: Conquistas e Perspectivas. Química Nova, v. 25, Supl. 1, p.14-24, jul, 2002.

VAILLANT, D.; MARCELO, C. Ensinando a ensinar: As quatro etapas de uma aprendizagem. Denise Vaillant, Carlos Marcelo. - 1. Ed. Curitiba: Ed. UFTPR, 2012. 